\title{
Towards conceptualizing reverse service supply chains
}

Article

Accepted Version

He, Q., Ghobadian, A., Gallear, D., Beh, L.-S. and O'Regan, N. (2016) Towards conceptualizing reverse service supply chains. Supply Chain Management: An International Journal, 21 (2). pp. 166-179. ISSN 1359-8546 doi:

https://doi.org/10.1108/SCM-01-2015-0035 Available at https://centaur.reading.ac.uk/62913/

It is advisable to refer to the publisher's version if you intend to cite from the work. See Guidance on citing.

Published version at: http://dx.doi.org/10.1108/SCM-01-2015-0035

To link to this article DOI: http://dx.doi.org/10.1108/SCM-01-2015-0035

Publisher: Emerald

All outputs in CentAUR are protected by Intellectual Property Rights law, including copyright law. Copyright and IPR is retained by the creators or other copyright holders. Terms and conditions for use of this material are defined in the End User Agreement.

\section{www.reading.ac.uk/centaur}

\section{CentAUR}

Central Archive at the University of Reading 
Reading's research outputs online 


\section{Towards conceptualising reverse service supply chains}

\section{Introduction}

The supply chain concept is increasingly branching out from manufacturing services (e.g. Sampson, 2000; Ellram et al., 2004; Giannakis, 2011; Lillrank et al., 2011; Vries and Huijsman, 2011; Shi and Liao, 2013). Reverse flow, closed-loop supply chains are an important current focus of research (Mondragon et al., 2011; Govindan et al., 2015). These concepts are predicated on the maximization of value creation, securing sustainable development opportunities throughout products lifecycle, and dynamic value creation from different types of returns over time (Govindan et al., 2015). To date, the manufacturing has provided the context for the majority of reverse supply chain (RSC) research (e.g. Jayaraman et al., 1999; Blackburn et al., 2004; Jayaraman and Luo, 2007; Huang et al., 2013; Mafakheri and Nasiri, 2013; Chuang et al., 2014). The interest in the reverse service supply chain (RSSC) is more recent and nascent in nature.

How significant is RSC in the service sector and, conceptually, what are the key design issues? The answers to these two questions matter because of the service sectors' share of gross domestic product (GDP) and its heterogeneity. The service sector is the largest contributor to the GDPs of the developed economies. For example, in the United States the service sector accounts for 68\% of GDP and four out of five jobs (OUSTR, 2014), and in the UK it accounts for around 78\% of GDP (ONS, 2014). The significance of the service sector is growing rapidly within the emerging and developing economies. The service sector is both broad and inherently heterogeneous, points discussed more fully in the next section. This heterogeneity affects both the importance and the design of forward and RSSC ; hence no single RSC model is capable of depicting the service sector as a whole.

Service supply chains (SSC) possess different characteristics to manufacturing supply chains (Sampson, 2000), hence, RSSC need to be conceptualized differently in order to capture the unique characteristics of diverse groups of services. The research examining the RSSC is showing potential, but is sparse, thus limiting our understanding (Sampson, 2000; Bienstock et al., 2011). The growing significance of services calls for greater research effort developing conceptual understanding, guiding empirical research and facilitating more effective RSSC operations in practice.

The aim of this paper is to develop a conceptual model / typology of forward and RSSC. We first develop a two-dimensional service firm typology based on output tangibility/intangibility and input customized/standardized continuums as they impact the design of forward and RSC The proposed SSC typology potentially aids future theoretical / empirical research as well as the practicing managers by highlighting significance of operations and the design characteristics enabling them to better address potential RSC issues.

This section is followed with the review of the extant literature. Next we define forward and reverse service supply chains, followed by a discussion of the methodology. In Section 4 we introduce our two-dimensional matrix that serves as the foundation for our conceptual model and typologies (section 5) We conclude by discussing the implications and draw conclusions .

\section{Literature review}


The current RSC research focus is primarily on manufacturers reverse flow (e.g. Jayaraman et al., 1999; Blackburn et al., 2004; Jayaraman and Luo, 2007; Huang et al., 2013; Mafakheri and Nasiri, 2013; Chuang et al., 2014). The few existing studies examining RSSC rely on manufacturing concepts or service activities are treated as supporting functions of the manufacturing supply chain (Amini et al., 2005; Bienstock et al., 2011). .

\subsection{Heterogeneity of service supply chains}

The diversity and context dependency of SSC contributes to the paucity of conceptual RSSC studies (Sampson, 2000; Ellram et al., 2004; Giannakis, 2011). Compared with manufacturing supply chains, service supply chains are heterogeneous in nature for five reasons.

First, services encompass almost all economic activities apart from agriculture, mining and manufacturing (Goodman and Steadman, 2002; Ellram et al., 2004). Heterogeneity not only occurs between sectors, but also exists within sectors affecting the design and operation of both forward and reverse supply chains (Veronneau and Roy, 2009),

Second, service value chains display significant variations between and across sectors. According to Porter (1985), value is what buyers are willing to pay and the value chain consists of a set of primary and support activities that an organization carries out to create value for its customers. In some sectors, service elements dominate the value chain as primary activities creating the majority of value for the customer, for example, consultancy services, education, and finance. However, in other sectors service contribution to value creation is more balanced vis-à-vis other elements of the value chain. For example, in retail, in-bound logistics and the effectiveness of operations also make significant contributions to the creation of value.

Third, the value chain processes of service firms are much less standardized compared to those of typical manufacturing firms. Service firms' outputs display significant variations and uncertainties due to the sizeable human involvement (Sengupta et al., 2006). Furthermore, the requirements and expectations of customers can be very different from case to case (Schmenner, 1986; Sampson, 2000). Fourth, service provision largely tends to be decentralized (with some notable exceptions), because decisions are generally taken locally to meet the varied customer requirements (Sampson, 2000; Sengupta et al., 2006). Moreover, when services are outsourced, the procurement of services is often not centrally managed but based on local requirements (Ellram et al., 2004). Hence, outputs are also likely to vary from case to case.

Fifth, uncertainties in processes due to significant human involvement and the variations in service outputs due to varied customer requirements tend to make service evaluation and performance measurement highly complex and differentiated (Ellram et al., 2004). In turn, this compounds the complexities of service supply chain standardization and conceptualization.

\subsection{Products as bundles of goods and services}

Sampson (2000) argued that services are not solely intangible and their provision is often dependent on facilitating goods. According to Davis and Heineke (2003) service products can be viewed as bundles of goods and services across a continuum, with groceries at one end, having close to $100 \%$ facilitating goods, and consultancy at the other end, with close to $100 \%$ intangible provision and other services in between. 
Services, depending on their continuum position, will possess different operational characteristics (Davis and Heineke, 2003; Ellram et al., 2004). Hence, a one-modelfits-all approach will not suffice.

The previous research focused on services offering intangible product (output) bundles capturing the position at one end of the continuum (e.g. Sampson, 2000; Ellram et al., 2004; Giannakis, 2011). These do not necessarily reflect the realities of forward and RSC of services occupying other positions on the continuum. In this paper we attempt to differentiate between the forward and RSSC utilising critical distinguishing dimensions. We maintain that a clear typology will allow for a more fine grained representation of forward and RSSC.

\subsection{Towards definitions of forward and reverse service supply chain}

Traditional definition of supply chain management (SCM) does not readily apply to services. Hence, , Ellram et al. (2004, p. 17) defined SCM for services as: "the management of information, processes, capacity, service performance and funds from the earliest supplier to the ultimate customer". The focus here was service operations outsourcing limiting its scope.

Johnson and Mena (2008, p. 28) provided a similar definition, but with a focus on servitization strategy. They defined supply chain management of servitized products as "the management of information, processes, capacity (people, equipment and facilities), products, services and funds from the earliest supplier to the ultimate customer".

As Albino et al. (2002, p.119) suggested, "a supply chain can be analysed as a network of production processes. Each process can be defined as a system that produces output flows in consequence of input flows". From this perspective, a service firm is a value adding unit transforming inputs into service outputs. As such SSCs entail flow of non-physical inputs and outputs, or a bundle of physical and nonphysical inputs and outputs. The flow of information, funds, and intangible and tangible inputs and outputs are common to all services. The differences arise from the tangibility and/or intangibility of inflows and outflows, which vary significantly from one service firm to another regardless of whether they belong to the same or different standard industrial code (SIC).

In this paper we rely on a single broad definition of service supply chain management defined as: "the management of the flow of information, funds and materials between the service firm, its earliest suppliers and the ultimate customer in the process of transforming tangible and/or intangible inputs into tangible and/or intangible service output valued by the customer". We do not specify the direction of flows as flows are bi-directional not least because of the "customer-supplier duality" highlighted by Sampson (2000).

In manufacturing the direction of flow determines whether the supply chain is forward or reverse. For example, the American Reverse Logistics Executive Council defined RSC as "the process of planning, implementing, and controlling the efficient, cost effective flow of raw materials, in-process inventory, finished goods and related information from the point of consumption to the point of origin for the purpose of recapturing value or proper disposal" (Govindan et al. 2013, p. 320). However, as Blackburn et al. (2004) noted, not all reverse manufacturing supply chains possess similar characteristics; the dissimilarities are accentuated in the case of service organizations because of the heterogeneity discussed previously. For service supply chains it is more difficult to identify the reverse supply chain simply by the direction of flow of information or inputs, because it is very likely that a service supply chain 
will have bi-directional flows of information/inputs and will have multiple input points (Sampson, 2000). Hence, a different approach for defining the RSSC is needed.

Another approach for identifying the RSSC is to consider triggers, simply because the reverse flow is logically instigated by an event, for example, when customers become dissatisfied with the service or want to cancel the service contract, or when they want to return the tangible part of a service output that may have become faulty or reached the end of its useful life. Consequently, it is reasonable to identify the RSC through triggers. Therefore, we define RSSC management as "the process of planning, implementing and controlling the efficient and cost effective flow of tangible and/or intangible input and output between the point(s) of consumption and the point(s) of origin, induced by a service cessation event, for the purpose of recapturing value or proper disposal". This definition, again, does not restrict the direction of flow of input/output to the RSC; instead it recognizes all possible flows of intangible and tangible inputs and outputs.

\section{Methodology}

We take our lead from Meredith (1993), arguing that conceptual model building creates a balance between inductive and deductive reasoning enabling academics to lead and guide managerial practices. We broadly follow the methodology suggested by Meredith (1993) deployed by other SCM scholars (e.g. Carter and Rogers, 2008). Figure 1 illustrates the process we followed. First, we reviewed the relevant literature identified through a rigorous search of two major databases - the $\mathrm{ABI} / \mathrm{Inform}$ and EBSCO - using keywords such as as: service/supply chain, service/supply chain management, service/reverse supply chain, service/closed/closed-loop supply chain, and in each case we conducted the search with the word "service" included and with it excluded. Each search iteration was preceded by terms such as definition, theory, concept, model, typology and inductive/deductive research. An extensive database of relevant literature was developed through initial searches.

We then examined this literature in detail and, based on our initial reading, conducted further searches adding additional literature to our database. This phase, in particular, involved consulting books referred to by papers in our database. The conceptual development is the product of the integration of different works, summarizing common elements through extensive discussions, contrasting the key concepts, synthesizing the outcomes of our findings and applying "logical deduction" along the lines suggested by Wacker (1998) and Handfield and Melnyk (1998).

\section{[Insert Figure 1 about here]}

We used the previous literature (see Table 1) to identify key dimensions of service typology and narrowed these down to dimensions helpful in the classification of reverse/closed-loop supply chains. These dimensions (standardization of process and input, and tangibility of expected service output) were used as the basis for the development of a two-dimensional matrix (see Figure 2, in section 4)). We then used this typology, our summary of the literature, extensive discussion, and logical deduction to develop four archetypal service clusters (see Figure 2).

[Insert Table 1 about here] 
We drew on the knowledge of four field experts in our effort to identify the four archetypal service clusters. Expert selection criteria were: (1) alignment between knowledge and research field; (2) publications in leading journals; and (3) research leadership. Panel of experts offer opinion diversity, independence, knowledge decentralization, and opinion aggregation (VandeVen and Delbecq, 1974). We used a variant of Delphi technique based on populated charts to obtain experts' opinions on the archetypal service clusters. (VandeVen and Delbecq, 1974) but Experts were asked to independently name some typical services or service firms and note each service on separate cards. They were then asked, independently, to place their cards onto the two-dimensional matrix that had been developed. A researcher then compared the four independently populated charts, noting the area of the chart on which the cards were placed as well as similarities and differences. Thirty different services were identified by the experts, while 18 of those services were shared between experts, within these 18 shared services 12 were put into the same quadrant by all four experts yielding an inter-rater reliability of $66.7 \%$ (Gwet, 2014). Where there were differences the experts were consulted to ascertain the logic of their choice. The aim was to gain consensus, but where this was not forthcoming a simple majority rule was applied. In the event there were only a few such cases and experts reached consensus during the interview stage described below. The process enabled the development of a single consolidated chart with services having similar characteristics being grouped in an appropriate quadrant.

To enhance reliability, one of the researchers conducted a short open-ended interview with each of the four experts independently, asking them to comment on why they had placed the service in a particular quadrant and whether the overall typology was robust. Services placed in a particular quadrant based on the majority rule (mentioned above) were highlighted and consensus was reached at this stage. The literature was revisited, using the service typology we had developed, in order to specify and illustrate the basic structure and activities of the forward and the corresponding RSSC of firms belonging to each archetypal service organization. The unit of analysis was service firm. As a result of this process four forward and reverse supply chain models were developed for each archetypal service firm cluster. This culminated in a typology of forward and RSSCs (see Figure 3, in section 5).

With the set of preliminary conceptual models ready, we followed a similar approach to Lyles (1990) and Carrol (1994) by developing an open-ended questionnaire and conducting a survey of academic experts world-wide to verify the veracity and relevance of the proposed parsimonious conceptual models. We identified a panel of 52 academic experts who had published in the previous five years in leading journals, focusing on green or reverse logistics and supply chain, service characteristics, service operation, service classification, service logistics, service procurement including public organizations, and SSC.

We developed the open-ended questionnaire using Qualtrics - a popular internetbased survey engine - allowing a combination of diagrams and text within the survey instrument. The questionnaire was designed to ascertain the experts' views on the two-dimensional service typology and the four parsimonious models, as well as the definitions of key terms, such as forward and RSSC, service input and output, and the examples of archetypal services. Respondents were asked: (1) to what extent does the service typology accurately capture the different types of services? (2) are there any service types not covered by this typology? and (3) to what extent does each of the four conceptual models represent the essential characteristics of the forward and RSSCs of different type of services? The survey was included in the invitation email 
sent to our panel of academic experts as a hyperlink. We received 39 responses, but only 21 were fully completed resulting in an effective response rate of $40.38 \%$. This compares favourably with responses received by previous researchers targeting similar population (Lyles, 1990). Table 2 summarizes the basic profiles of the respondents.

\section{[Insert Table 2 about here]}

Two of the authors independently reviewed the responses and noted the emerging themes independently before comparing and synthesizing the responses. The two authors had a consistent interpretation to most of the open-ended responses, and reached consistency on a small number of responses with discrepancies after open discussion. While most of the respondents generally agreed with the efficacy of the typology and the parsimonious conceptual models, discrepancies in opinions were reviewed by undertaking further review of the literature to improve and refine the preliminary conceptual models in order to reach the final parsimonious conceptual models.

\section{Towards a service typology}

Services heterogeneity makes it difficult to develop a grand conceptual model/theory of service firms (Verma and Boyer, 2000). To advance our nascent understanding of service firms' forward and RSCs we need to develop clusters of service firms with common characteristics relevant to the conceptualization of their forward and RSCs reverse supply chains. Therefore, construction of a robust service typology is a critical first step in the advancement of a conceptual reverse/closed-loop SSCs. To this end, we carefully examined the typologies proposed by leading scholars in the field, including those of Judd (1964), Rathmell (1974), Shostack (1977), Sasser et al. (1978), Hill (1977), Kotler (1980), Chase (1981), Lovelock (1983), Schmenner (1986; 1995), Mersha (1990), Chase and Hays (1991), and Kellog and Nie (1995) (see also Table 1), in the light of definition of RSSC.

Product seems a logical dimension of a service typology designed to dovetail with the development of conceptual models of the reverse/closed-loop supply chain. It was central to typologies developed by Shostack $(1977 ; 1982)$, Sasser et al. (1978), Goodman and Steadman (2002), and Davis and Heineke (2003). We used the idea of proportion of goods and services making up a product suggested by Davis and Heineke (2003) to delineate one dimension of our typology because it can be objectively assessed. Moreover, it fits with the current definitions of a reverse/closedloop supply chain, and it is the foundation of a number of prominent existing typologies.

In assessing the proportion of tangible goods and services making up a product, it is not sufficient to solely consider the product bundle. Rather, it is crucial to consider how the product bundle is viewed by customers. For example, the core bundle offered by mobile telecommunications companies comprises mobile voice and data services. To reach the market all the companies have retail businesses, and the design and function of handsets is also highly valued by customers. Another common element in definitions of the reverse/closed-loop supply chain is "value generation", which in turn is process driven (Silvestro et al., 1992; Hill et al., 2002). To this end, a number of scholars have argued that manufacturing process labels, namely one-off or project, 
batch, or continuous process, can also be applied to service firms' processes (Sasser et al., 1982). Others have argued that such classifications do not fully take into account the inherent variability created by customer requirements (Silvestro et al., 1992). To address this criticism, some researchers have developed process typologies using the extent of service customization, so that at one extreme service processes are highly customized to meet the needs of each customer, and at the other extreme standardized processes are deployed to produce the desired product bundle (Maister and Lovelock, 1982; Kellog and Nie, 1995). We extend this classification and suggest that services can be produced through either customized/non-standardized processes and inputs or standardized processes and inputs.

By linking the two elements found commonly in the definitions of reversed/closedloop supply chain with the previous service sector typologies, we developed a twodimensional matrix reflecting the characteristics of key clusters of services pertinent to such supply chains (see Figure 2). Later, we use this matrix to develop the structure of forward and RSCs of service organizations falling within each of the four service clusters identified.

As shown in Figure 2, the horizontal axis represents the degree of tangibility of the service output. The vertical axis represents the degree of standardization of the process and input. Four clusters of services are therefore indicated by this matrix.

\section{[Insert Figure 2 about here]}

For the Type I cluster of services, the service output (product bundle) is typically intangible as valued by customers, but the process of producing the output relies on customized input. Examples include medical services, business consultancy, architectural services, education and repair services.

For the Type II cluster of services, the service output (product bundle) is typically tangible, but the process of producing the service is normally customized. A Saville Row tailor offers a customized product and process, which is valued highly by the customer. For the Type III cluster of services, the service output (product bundle) is typically intangible as valued by customers, and producing the service normally relies on standardized processes and inputs. Typical examples are telecommunication services, passenger transport, amusement parks and cinemas. For this type of service, the service outputs are typically intangible in the form of experience, aesthetics or recreation (Goodman and Steadman, 2002). The same standardized resources are dedicated to different customers, although sometimes with limited levels of variation.

For the Type IV cluster of services, the service output (product bundle) is typically tangible as valued by customers, and the process of producing the service relies heavily on standardized inputs. Typical examples are retailing, car dealerships and grocery stores. Generally, these types of services tend to fit at the end of the manufacturing supply chain handling the product distribution from the manufacturer to customers.

Our verification process (feedback and interview with the four field experts plus survey of leading academics' opinions) suggests that the proposed typology does not imply absolute homogeneity within clusters but rather signifies substantial similarity in relation to the chosen dimensions.

\section{Forward and reverse service supply chains illustrated}


Based on the two-dimensional typology matrix (Figure 2) and the survey responses, we now discuss conceptual models illustrating the characteristics of the forward and corresponding RSCs for each of the four service clusters. As our aim is to develop pertinent insight into the main structure of the forward and RSSCs, we do not include flow of funds and information in our conceptual models. Instead we focus on the main input and output flows within the SSC. Moreover, we do not extend our conceptual models beyond the first-tier suppliers, to give a clear conceptual view of the main value adding activities of the focal service firm. To assist we have developed a simple schematic for each of our four archetypal forward/RSCs reverse supply chains highlighting their key features (see Figure 3). A more detailed discussion is provided in the following sections.

[Insert Figure 3 about here]

\subsection{Type I forward and reverse service supply chain}

In the case of Type I cluster, the intangible elements are valued highly by customers. The purchasing process entails transfer of the intangible outputs such as suppliers' capacity, information or knowledge, to the clients (Ellram et al., 2004). As the survey respondents pointed out, in exceptional circumstances there may be some minor transfer of tangibles. In the main physical goods involved play a facilitating role. Moreover, the deployment of tangible inputs by the service firm is relatively small compared to the value added serving a supporting role in the value chain (Porter, 1985). Therefore, the conceptual model (see Figure 4) does not include tangible outputs as a major flow from the service firm to customers.

Instead, intangible inputs, such as data, information, and knowledge, are converted into intangible service outputs (see Figure 4). The conversion of customer requirements into service outputs is highly heterogeneous varying from case to case. The provision of Type I services is crucially reliant on the knowledge and expertise of the service firm personnel. The provision of Type I services requires intangible inputs , such as knowledge, information, expertise and experiences. In this sense, the forward supply chain of a Type I cluster of services is more of an intangible supply chain.

Furthermore, as indicated by "customer-supplier duality", customers themselves are also suppliers of information or inputs - that is, they are both a recipient of the service and a necessary input enabling the service to be performed (Sampson, 2000). Therefore, in the forward supply chain of a Type I cluster of services, there is simultaneous backward flow of intangible or tangible inputs from the customer to the service firm. Hence, the flow of intangible or tangible input in this type of service is bi-directional, and the service firm is the hub of the input flows (see Figure 4).

[Insert Figure 4 about here]

For a Type I cluster of services, the RSC processes start, for example, when the customer returns with an uncomfortable condition after medical treatment, with a malfunctioning device after a repair service, or with unsatisfactory solutions from a consultancy firm. Since the service output is normally intangible and produced by non-standardized inputs and resources dedicated to the specific customer, it is very unlikely that the original service output can be returned as with physical goods. Therefore, the start of the RSC for Type I services invariably triggers a new forward 
supply chain (see Figure 4). The forward and the RSC are likely to be the same for a Type I service clusters although the RSC may be smaller in scale than the original forward chain, because fewer resources or inputs may be required to undertake the rework.

\subsection{Type II forward and reverse service supply chain}

For Type II service clusters s, customer requirements are bespoke and vary from case to case. Customized resources and inputs are deployed according to specific customer requirements. Unlike Type I services, the output bundle for Type II services includes a larger tangible element. According to the survey respondents although the intangible element of output contributes significantly to the service value added, tangible inputs and outputs are critical for this cluster of services. Type II SSC more closely mimic manufacturing supply chains, but the service is highly customized and customer driven (Figure 5). Suppliers to Type II services will normally supply tangible inputs to the service firm, such as parts, ingredients, components, and materials. The service firm will then deploy its in-house expertise to convert these tangible inputs into tangible and intangible service outputs. For this type of service, customer information, personal data and preferences are important intangible inputs. Therefore, the forward supply chain of Type II services has a bi-directional element between the focal service firm and its customers (Figure 5).

\section{[Insert Figure 5 about here]}

For a Type II service, the RSC is again likely to be triggered by customer dissatisfaction with the tangible service output. However, since the original service outputs are customized/personalized, it is likely that only a small proportion, if any at all, of the original tangible service output can be returned to the supply chain directly for reuse. Interestingly a survey respondent commented "an over-cooked dish cannot be re-cooked or consumed by another customer once served"; "a refurbishment is likely to be modified in situ" (although some removable fixtures can be returned); "a tailored dress/suit is also likely to be modified and if this is not possible, the suppliers of the textiles are unlikely to find any value in taking back the highly modified (i.e. cut) material". The alternative is using second-hand retailers but this is unlikely because the service provider would not have the infrastructure and because of potential damage to the brand.

As with Type I services, for Type II services the start of the reverse supply chain process is likely to trigger the start of a new forward supply chain, since rework is normally needed (Figure 5). However, a small level of recycling or reuse of original tangible output maybe possible for Type II services.

\subsection{Type III service forward and reverse service supply chain}

The Type III cluster of services possesses the same expected service output characteristics as Type I services, in that the outputs expected by customers are generally intangible. There is essentially very limited or no flow of tangible outputs from the service provider to the customer. These services generally involve the transfer of experiences or capability to the customer, or physical transformation (e.g. transportation) (Ellram et al., 2004). Even if there is a flow of tangible output between the service firm and the customer, it will account for a very small proportion of the 
service value offered to the customer. Here unlike Type I services, the conversion of customer requirements into service output is normally much more standardized and does not vary significantly from customer to customer. To perform the service the firm will deploy standardized tangible or intangible inputs. . Therefore, alongside a relatively small degree of intangible input flow generated by limited customer input choices, for Type III services there is significant tangible input flow from suppliers to the service firm (Figure 6).

Moreover, compared to Type I services, although customer information or personal data are an input to the service process, as pointed out by a survey respondent, they are not the key inputs to Type III service processes. The concept of "customersupplier duality" (Sampson, 2000) is much less prevalent. Therefore, we do not consider customer input as an important input flow in the forwards supply chains of Type III services (Figure 6).

\section{[Insert Figure 6 about here]}

For Type III services, the main service outputs are intangible experiences. Such intangible output cannot be returned like physical goods. A service output purchased or consumed by the customer in most cases cannot be reversed; it can only be exited/stopped by the customer (and possibly a refund issued). Therefore no reverse flow of output from customers can be identified (see Figure 6). However, in some Type III services, such as telecommunications, facilitating goods such as internet modems could be returned for reuse; similarly, in others, facilitating goods such as vehicles have recyclable materials which can be reclaimed.

The equipment, facilities and infrastructure used to provide many examples of Type III services are usually dedicated for specific purposes, and consequently it is normally unlikely for the service firm to be able to return bundles of its fixtures, facilities and equipment back to the suppliers. To restore the right level of service, the suppliers will normally rework or reinstall the facilities and infrastructures for the service firm, although the scale of rework may be smaller than the original input. Meanwhile, suppliers may renew necessary intangible inputs, such as training and information supply. As such, although both tangible and intangible inputs are needed for the forward supply chain of the Type III cluster of services, only the tangible part of the inputs may be returned to the supplier in the reverse supply chain for recycle or reuse (Figure 6).

\subsection{Type IV forward and reverse service supply chain}

For a Type IV cluster of services, the output valued by the customer is normally highly tangible. The provision of the service to the customer is primarily entails distributing standard tangible goods from the supplier to the customer. The service firm is typically located at the end of a manufacturing supply chain with the upstream manufacturer or wholesaler of tangible goods being their main supplier. The direction of flow of the tangible goods is from the supplier to the service firm and then to the customer (i.e. uni-directional). Moreover, the conversion of any customer requirements into output is highly standardized with small variations from customer to customer.. Alongside the tangible goods to be distributed, the Type IV cluster of services will deploy standardized tangible or intangible inputs and resources, such as point of sales (POS) devices, shelves and employees trained to a standard specification (e.g. sales personnel) to perform the service. Thus, there will be tangible 
and intangible input flows from other suppliers to the service firm, which are separated from the suppliers of goods to be consumed by the customer (see Figure 7).

[Insert Figure 7 about here]

The reverse supply chains of a Type IV cluster of services start when customers returning their tangible service output (i.e. goods). With the exception of rapidly perishable goods (e.g. retail groceries), since the outputs of Type IV services are more tangible and standardized, it is likely that a high proportion of those outputs can be returned back to the supply chain. While the flow of tangible goods is reversed in the RSC, standardized tangible or intangible inputs and resources are still required by the service firm to carry out its service. Thus, there will be continued forward flows of tangible and intangible input from other suppliers to the service firm (see Figure 7).

\section{Discussion and implications}

Services heterogeneity makes it almost impossible to develop grand theories/concepts. The forward and RSSCs follow this general rule. A better understanding of the characteristics of forward and RSSCs is predicted on the development of an appropriate service typology. We developed such a typology using two dimensions critical in the design and understanding of the forward and RSSCs the degree of output tangibility and level of standardization of inputs and processes underpinned by the extant literature, field experts' comments and interviews, and an extensive survey of leading academics. We then developed forward and RSCs for each cluster, testing their veracity deploying our three stage process. The characteristics of four archetypal of forward and RSSC are summarized in Table 3, showing their unique characteristics and commonalities as well as the configuration of the main inputs and outputs flows and their direction in the value-adding process.

We identify how significant the reverse operation is and describe the differences between the forward and RSC processes. These differences are governed by service bundle's level of tangibility. For Type I services, the role of the reverse supply chain is "perfunctory", since the RSC is limited to recycling facilitating goods or engaging in minor reworking. RSC is identical to the forward supply chain but smaller in scale. For Type II services, RSC plays a "moderate" typically concerned with small scale recycling of tangible output from the customer or return of faulty tangible inputs to original vendors. For Type III services, the role of RSC is "restricted", since its function is limited to recycling facilitating goods that are substantial in nature. For Type IV services, the role of RSC is "weighty" as there is significant opportunity for recycling of tangible goods - a significant element of the service.

\section{[Insert Table 3 about here]}

The following arise from the delineation of the different characteristics of the forward and RSCs. First, services deploying non-standardized inputs to produce bespoke outputs are generally dependent on customer inputs - data, information, service users - resulting in bi-directionality in the forward supply chain. Second for these services, the start of the reverse supply chain will normally trigger a new forward supply chain because the service output generated will vary from customer to customer to meet individual requirements. It is unlikely therefore that the original output would be returned back to the supply chain directly. Hence, RSC operates as as a forward 
"rework" chain. There may also limited opportunity for re-using / re-cycling some of the facilitating goods.

Third, services deploying non-standardized e inputs to produce bespoke outputs require greater operational flexibility and human resources versatility. The operations system and human capital may need adjustment from customer to customer, thus making quality consistency and service level maintenance more difficult in both the forward and RSC. Especially when the reverse process is triggered by an unsatisfied customer or service failure, it is more critical for the service firm to reconfigure its resources and human capital to recover its services. According to the service recovery literature (e.g. Hart et al., 1990; Spreng et al., 1995; Webster and Sundaram, 1998; Miller et al., 2000), customer loyalty will be maintained if adequate efforts are made to create rapid response to customers, to empower employees to generate local solutions and possibly to utilize customer criticism as an input to service recovery.

Fourth, the more tangible the output component of the service bundle, the higher the proportion of the service output that could be returned in the reverse supply chain for recycling, reuse or resale (or disposal). Intangible service outputs do not readily lend themselves to be "reversed"/returned once consumed or once the service-delivery process has commenced. Instead, they can only be stopped, or sometimes reworked. Thus, it is not feasible to reverse intangible elements of service along the supply chain, which is very different from RSC of manufacturing firms (e.g. Lau and Wang, 2009; Govindan and Popiuc, 2014).

\subsection{Practical Implications}

The service and forward and RSC typologies presented in this paper offer practicing managers a classification system enabling them to better design their forward and RSCs. The typologies clarify and group together services based on service bundle and customisation of inputs and process, , nature of relationship with customers, and the characteristics of service delivery system. This in turn helps managers to decide on an appropriate level of focus, time, and investment in designing and operating their forward and RSC. Supply chain, relationship with suppliers, and channels of distribution are among critical elements of firms' business models. They assume greater importance in service firms because customers and the information they provide are among important component inputs of and integral to channels of distribution. The typologies presented in this paper help mangers to better align the internal elements of their business model an important source of competitive advantage. Furthermore, they help with external alignment and deeper appreciation of supply chain contributes to business model innovation.

Another key practical point concerns the increased risk of service inconsistency inherent in high reliance on customized /non-standardized inputs (Ungan, 2006). To mitigate this risk an effective documentation and talent-retention system is required (Ungan, 2006). This in turn will reduce the need for re-work, hence, result in cost reduction and shorter re-cycle lead-time increasing the effecience of the RSC. Although input standardization can reduce supply chain risks and improve consistency in forward and reverse service supply chains, in reality process standardization and output variation can be a trade-off. Managers need to balance the degree of input standardization and output variation to ensure acceptable service levels are maintained while the cost and extra complexity caused by reverse supply 
chain process are minimized. For Type I and II services issues with output is likely to lead to increased costs with no cost recovery opportunity.

hence, the best way of reducing the costs of the reverse supply chain is not allowing it to happen (Miller et al., 2000).

\subsection{Research Implications}

For academics, the conceptual models of forward and RSCs and the subsequent typology offer the basis for identifying research gaps and better ordered exploration of RSSCs. Our proposed typology along with the review of the extant literature suggests an imbalance in the research effort. Most of the previous research has focused on Type IV RSSC (e.g. Bienstock et al., 2011; Ruiz-Benitez and Muriel, 2014), while the consideration of Type I, Type II, and Type III services is very sparse. More importantly, the typology allows theoretical developments for each cluster of services and their forward and backward service supply chain and better focused empirical research.

It was not our intention to provide a fine-grained specification of the actual value chain process through which service outputs are produced. For example, we do not include the flow of information in our conceptual models, unless the flow of information forms an important service input, as in the case of Type I and Type II services. This is because the service sector is highly heterogeneous and our intention was to provide, as clearly as possible, a differentiation between the four service clusters and their resultant forward and RSC focusing on primary value-adding activities. In doing so, , we highlight the distinct characteristics of forward and RSC of each cluster of firms. Future researchers, however, could extend our conceptual models by adding flows of funds, information and knowledge, developing a a finegrained representation of supply chains of firms in each cluster.

It is also important to note that, some services and their associated forward and RSC may fall on or close to the boundaries delineating the four clusters, a common issue with all typologies. A point alluded to by a number of experts participating in our survey. For example, a cruise ship offers a bundle of both intangible and tangible outputs, based on both standardized and customized service outputs (Veronneau and Roy, 2009), thus having characteristics of different RSSC. This raises an important point concerning the level of analysis for future researchers using our typology and conceptual models. Many service firms provide a combination of different types of services. For example, a cinema nowadays is likely to offer movie screening (Type III), restaurant facilities (Type II) and retail merchandising (Type IV) at the same time. A medical tourism service combines medical service (Type I) and tourism (Type III) (Lee and Fernando, 2015). Therefore, for future researchers the choice of unit of analysis assumes greater importance, for example, the firm or its business units. It may be more pertinent to focus on the forward and RSC of the business unit to develop a finer grained understanding. Our typology helps researchers to better chose their unit of analysis.

\section{Conclusions}

Prior research has tended to apply manufacturing-oriented frameworks directly or with limited modifications to examining service supply chain management (Swank, 2003; Ellram et al., 2004; Giannakis, 2011). Hence, limiting the opportunity for developing generalizable service specific theories. Here we present the basic structure 
of forward and the corresponding RSSCs related to four general service clusters. The conceptual models presented will help future researchers and practitioners to better clarify the processes of the forward and RSC of each cluster of service firms, and to develop better solutions to reduce service gaps, optimize service value chains, and enhance the potential for value re-capture or creation from RSSC activities. We explore both forward and RSC for each of our clusters because we firmly establish that forward and RSC are no mutually exclusive,. This is particularly important given the limited previous research addressing the service firms supply chain.

This paper, while making a unique contribution, has a number of limitations leading us to propose areas for future research. First, our conceptual models serve as a starting point and it may not neatly fit all the different types of service provision. In reality there may be many services that fall at the intercept of our typology matrix, or there will be some exceptions not fitting into our typology matrix. However, our typology is more of what Kellog and Nie (1995) referred to as a "midrange" typology of services, which restricts the scope to more manageable segments, rather than a "grand" typology capable of embracing all organizations. Therefore most service firms will fit into the matrix or find useful insights from using the service typology and the related forward and RSSC typology. However, alternative typologies may be needed to cater for some services, and there may be other ways of categorizing SSC to augment our conceptualization of RSSC. Future researchers may wish to explore other dimensions of service classification to develop finer grained classification schemes.

Second, as was pointed out by experts responding to our survey, we do not claim that the four parsimonious conceptual models are an absolute representation of all services. Our models can be criticized as being oversimplified, particularly given the breath covered by service firms. However our conceptual models will allow for easier evaluation and comparison of different service firms' forward and RSCs. Our conceptual models provide a starting point for examining the variation and commonalities in forward and RSSCs and they pave the way for a more focused conceptualization of service supply chains.

Third, the conceptualization of forward and RSCs in this paper does not extend to the network structure of many supply chains, or incorporate the dimension of supply chain collaborations (Chakraborty et al., 2014; Lee and Fernando, 2015). In our conceptual models we did not extend the supply chain beyond first-tier suppliers or customers. This is because we sought to bring a high level of initial clarity to the conceptual models. Future research could elaborate more on the extended network structure of the service supply chains and on collaborative relationships between service supply chain actors.

\section{References}

Albino, V., Izzo, C. and Kuhtz, S. (2002), "Input-output models for the analysis of a local/global supply chain", International Journal of Production Economics, Vol.78, No.2, pp. 119-131.

Amini, M. M., Retzlaff-Roberts, D. and Bienstock, C. C. (2005), "Designing a reverse logistics operation for short cycle time repair services", International Journal of Production Economics, Vol.96, No.3, pp. 367-380. 
Bienstock, C. C., Amini, M. and Retzlaff-Roberts, D. (2011), "Reengineering a reverse supply chain for product returns services", International Journal of Business Performance and Supply Chain Modelling, Vol.3, No.4, pp. 335-352.

Blackburn, J. D., Guide, V. D. R., Souza, G. C. and Van Wassenhove, L. N. (2004), "Reverse supply chains for commercial returns", California Management Review, Vol.46, No.2, pp. 6-22.

Carrol, A. B. (1994), "Social issues in management research", Business and Society, Vol.33, No.1, pp. 5-29.

Carter, C. R. and Rogers, D. S. (2008), "A framework of sustainable supply chain management: moving toward new theory", International Journal of Physical Distribution \& Logistics Management, Vol.38, No.5, pp. 360-387.

Chakraborty, S., Bhattacharya, S. and Dobrzykowski, D. D. (2014), "Impact of supply chain collaboration on value co-creation and firm performance: A healthcare service sector perspective", Procedia Economics and Finance, Vol.11, No.0, pp. 676-694.

Chase, R. B. (1981), "The customer contact approach to services: Theoretical bases and practical extensions", Operations Research, Vol.29, No.4, pp. 698-710.

Chase, R. B. and Hays, R. H. (1991), "Beefing up operations in service firms", Sloan Management Review, Vol.33, No.1, pp. 15-26.

Chuang, C.-H., Wang, C. X. and Zhao, Y. (2014), "Closed-loop supply chain models for a high-tech product under alternative reverse channel and collection cost structures", International Journal of Production Economics, Vol.156, pp. 108123.

Davis, M. M. and Heineke, J. (2003), Managing Services: Using Technology to Create Value, McGraw-Hi11, Irwin.

Ellram, L. M., Tate, W. L. and Billington, C. (2004), "Understanding and managing the services supply chain", Journal of Supply Chain Management, Vol.40, No.4, pp. 17-32.

Giannakis, M. (2011), "Management of service supply chains with a service-oriented reference model: the case of management consulting", Supply Chain Management: An International Journal, Vol.16, No.5, pp. 346-361.

Goodman, B. and Steadman, R. (2002), "Services: Business demand rivals consumer demand in driving job growth", Monthly Labor Review, Vol.125, No.4, pp. 3-9.

Govindan, K. and Popiuc, M. N. (2014), "Reverse supply chain coordination by revenue sharing contract: A case for the personal computers industry", European Journal of Operational Research, Vol.233, No.2, pp. 326-336.

Govindan, K., Popiuc, M. N. and Diabat, A. (2013), "Overview of coordination contracts within forward and reverse supply chains", Journal of Cleaner Production, Vol.47, No.0, pp. 319-334.

Govindan, K., Soleimani, H. and Kannan, D. (2015), "Reverse logistics and closedloop supply chain: A comprehensive review to explore the future", European Journal of Operational Research, Vol.240, No.3, pp. 603-626.

Gwet, K. L. (2014), Handbook of Inter-Rater Reliability: The Definitive Guide to Measuring the Extent of Agreement Among Multiple Raters, Advanced Analytics, LLC, Gaithersburg, MD.

Handfield, R. B. and Melnyk, S. A. (1998), "The scientific theory-building process: A primer using the case of TQM", Journal of Operations Management, Vol.16, No.4, pp. 321-339. 
Hart, C. W., Heskett, J. L. and Sasser, W. E. J. (1990), "The profitable art of service recovery", Harvard Business Review, Vol.68, No.4, pp. 148-156.

Hill, A. V., Collier, D. A., Froehle, C. M., Goodale, J. C., Metters, R. D. and Verma, R. (2002), "Research opportunities in service process design", Journal of Operations Management, Vol.20, No.2, pp. 189-202.

Hill, T. P. (1977), "On goods and services", Review of Income and Wealth, Vol.23, No.4, pp. 315-338.

Huang, M., Song, M., Lee, L. H. and Ching, W. K. (2013), "Analysis for strategy of closed-loop supply chain with dual recycling channel", International Journal of Production Economics, Vol.144, No.2, pp. 510-520.

Jayaraman, V., Guide Jr, V. and Srivastava, R. (1999), "A closed-loop logistics model for remanufacturing", Journal of the operational research society, Vol.50, pp. 497-508.

Jayaraman, V. and Luo, Y. (2007), "Creating competitive advantages through new value creation: A reverse logistics perspective", Academy of Management Perspectives, Vol.21, No.2, pp. 56-73.

Johnson, M. and Mena, C. (2008), "Supply chain management for servitised products: A multi-industry case study", International Journal of Production Economics, Vol.114, No.1, pp. 27-39.

Judd, R. C. (1964), "The Case for redefining services", Journal of Marketing, Vol.28, No.1, pp. 58-59.

Kellog, D. L. and Nie, W. (1995), "A framework for strategic service management", Journal of Operations Management, Vol.13, No.4, pp. 323-337.

Kotler, P. (1980), Principles of marketing, Prentice Hall, Englewood Cliffs, NJ.

Lau, K. H. and Wang, Y. (2009), "Reverse logistics in the electronic industry of China: A case study", Supply Chain Management: An International Journal, Vol.14, No.6, pp. 447-465.

Lee, H. K. and Fernando, Y. (2015), "The antecedents and outcomes of the medical tourism supply chain", Tourism Management, Vol.46, pp. 148-157.

Lillrank, P., Groop, J. and Venesmaa, J. (2011), "Processes, episodes and events in health service supply chains", Supply Chain Management: An International Journal, Vol.16, No.3, pp. 194-201.

Lovelock, C. H. (1983), "Classifying services to gain strategic marketing insights", Journal of Marketing, Vol.47, No.3, pp. 9-20.

Lyles, M. A. (1990), "A research agenda for strategic management in the 1990s", Journal of Management Studies, Vol.27, No.4, pp. 363-375.

Mafakheri, F. and Nasiri, F. (2013), "Revenue sharing coordination in reverse logistics", Journal of Cleaner Production, Vol.59, pp. 185-196.

Maister, D. and Lovelock, C. H. (1982), "Managing facilitator services", Sloan Management Review, Vol.23, pp. 19-31.

Meredith, J. (1993), "Theory building through conceptual methods", International Journal of Operations \& Production Management, Vol.13, No.5, pp. 311.

Mersha, T. (1990), "Enhancing the customer contact model", Journal of Operations Management, Vol.9, No.3, pp. 391-405.

Miller, J. L., Craighead, C. W. and Karwan, K. R. (2000), "Service recovery: A framework and empirical investigation", Journal of Operations Management, Vol.18, No.4, pp. 387-400. 
Mondragon, A. E. C., Lalwani, C. and Mondragon, C. E. C. (2011), "Measures for auditing performance and integration in closed-loop supply chains", Supply Chain Management: An International Journal, Vol.16, No.1, pp. 43-56.

ONS (2014), "Index of services, October 2014", Office for National Statistics, Vol.23 December 2014, pp. http://www.ons.gov.uk/ons/rel/ios/index-ofservices/october-2014/index.html.

OUSTR (2014), "Services and investment: services", OUSTR, Vol.Retrived 01 January 2014, pp. http://www.ustr.gov/trade-topics/servicesinvestment/services.

Porter, M. E. (1985), Competitive advantage: Creating and sustaining superior performance, Simon and Schuster, New York.

Rathmell, J. M. (1974), Marketing in the service sector, Winthrop Publishers, Cambridge, MA.

Ruiz-Benitez, R. and Muriel, A. (2014), "Consumer returns in a decentralized supply chain", International Journal of Production Economics, Vol.147, Part C, pp. 573-592.

Sampson, S. E. (2000), "Customer-supplier duality and bidirectional supply chains in service organizations", International Journal of Service Industry Management, Vol.11, No.4, pp. 348-364.

Sasser, W. E., Jr., Olsen, R. P. and Wyckoff, D. D. (1978), Management of service operations: Text and cases, Allyn and Bacon, Boston, MA.

Sasser, W. E., Olsen, R. R. and Wyckoff, D. D. (1982), Management of Service Operations, Allyn and Bacon, Boston, MA.

Schmenner, R. W. (1986), "How can service businesses survive and prosper", Sloan Management Review, Vol.27, No.3, pp. 21-32.

Schmenner, R. W. (1995), Service operations management, Prentice Hall, Englewood Cliffs, NJ.

Sengupta, K., Heiser, D. and Koll, L. (2006), "Manufacturing and service supply chain performance: A comparative analysis", Journal of Supply Chain Management, Vol.42, No.4, pp. 4-15.

Shi, X. and Liao, Z. (2013), "Managing supply chain relationships in the hospitality services: An empirical study of hotels and restaurants", International Journal of Hospitality Management, Vol.35, pp. 112-121.

Shostack, G. L. (1977), "Breaking free from product marketing", Journal of Marketing, Vol.41, No.4, pp. 73-80.

Shostack, G. L. (1982), "How to design a service", European Journal of Marketing, Vol.16, No.10, pp. 49-63.

Silvestro, R., Fitzgerald, L., Johnston, R. and Voss, C. (1992), "Towards a classification of service processes", International Journal of Service Industry Management, Vol.3, No.3, pp. 62-75.

Spreng, R. A., Harrell, G. D. and Mackoy, R. D. (1995), "Service recovery: Impact on satisfaction and intentions", Journal of Services Marketing, Vol.9, No.1, pp. $15-23$.

Swank, C. K. (2003), "The lean service machine", Harvard Business Review, Vol.81, No.10, pp. 123-129.

Ungan, M. C. (2006), "Standardization through process documentation", Business Process Management Journal, Vol.12, No.2, pp. 135-148.

VandeVen, A. H. and Delbecq, A. L. (1974), "The Effectiveness of Nominal, Delphi, and Interacting Group Decision Making Processes", Academy of Management Journal, Vol.17, No.4, pp. 605-621. 
Verma, R. and Boyer, K. K. (2000), "Service classification and management challenges", Journal of Business Strategies, Vol.17, No.1, pp. 5-24.

Veronneau, S. and Roy, J. (2009), "Global service supply chains: An empirical study of current practices and challenges of a cruise line corporation", Tourism Management, Vol.30, No.1, pp. 128-139.

Vries, J. d. and Huijsman, R. (2011), "Supply chain management in health services: An overview", Supply Chain Management: An International Journal, Vol.16, No.3, pp. 159-165.

Wacker, J. G. (1998), "A definition of theory: Research guidelines for different theory-building research methods in operations management", Journal of Operations Management, Vol.16, No.4, pp. 361-385.

Webster, C. and Sundaram, D. S. (1998), "Service consumption criticality in failure recovery", Journal of Business Research, Vol.41, No.2, pp. 153-159. 